\title{
Triple Band Fractal Antenna for Radio Navigation and Fixed Satellite Services using Dragonfly Optimization
}

\author{
Ashwini Kumar ${ }^{1}$ and Amar Partap Singh Pharwaha ${ }^{2}$ \\ ${ }^{12}$ Department of Electronics and Communication Engineering, \\ Sant Longowal Institute of Engineering and Technology, Longowal, Sangrur, Punjab, India. \\ E-mail: ashwiniarya15@gmail.com
}

\begin{abstract}
This study reports the design, simulation, optimization and fabrication of a modified Hilbert curve fractal antenna for radio navigation and fixed satellite services. Modified Hilbert curve is applied on both lateral boundaries of radiator and upper boundary of ground plane. Dragonfly optimization technique is used to optimize the antenna dimension for improving the bandwidth. Proposed antenna resonates at $2.6 \mathrm{GHz}$, $4.4 \mathrm{GHz}$, and $8.7 \mathrm{GHz}$ having bandwidth of $0.2457 \mathrm{GHz}$, $0.700 \mathrm{GHz}$, and $4.1980 \mathrm{GHz}$ respectively. Maximum gain for the resonating bands is $3.6 \mathrm{~dB}, 5.5 \mathrm{~dB}$, and 7.3 $\mathrm{dB}$ respectively. Proposed antenna is characterized on the basis of various performance parameters like reflection coefficient, radiation pattern, gain and bandwidth. Proposed antenna is fabricated and tested for the validation of simulated results. Measured and simulated results are in good agreement.
\end{abstract}

\section{Introduction}

Present day wireless communication requires high performance antenna systems having conformal shape, aerodynamic profile, compact size, simple design and easy manufacturability. Moreover, such systems should be lighter in weight as well as cost effective too. In case of fixed satellite services (FSS) as well as radionavigation services (RNS), the situation becomes even more demanding in respect of these requirements. However, to meet these requirements, printed microstrip patch technology is used [1][2] frequently in these days for the fabrication of such high performance antenna systems. As FSS and RNS works in different frequency bands in different region of world, it demands multiband performance of antenna which can be attained by incorporating fractal geometry in microstrip patch antenna. Benoit B. Mandelbrot defined many patterns of nature [3] which are so irregular and fragmented in comparison of Euclid that Euclid leaves them as being "formless". He defined these irregular and fragmented structures as fractal after studying the morphology of these amorphous structures. Many fractal geometries are used in antenna designing like: sierpinski carpet, Koch curve, Hilbert curve and hybrid fractals [4][5][6][7]. A tri-band I slot microstrip patch antenna is presented in [8] designed for radar altimeter application which covers three bands $(4.4-4.7 \mathrm{GHz}),(5-$ $5.18 \mathrm{GHz})$ and $(7.3-15.9 \mathrm{GHz})$. RADAR altimeter is a device that is used to measure height of flying objects that is very useful information in navigation the object. In [9] a Triangular Sierpinski Fractal Antenna proposed which can be used for radar, satellite, aeronautical mobile, fixed mobile radiolocation and defense applications using X-band frequency. A CPW-fed fractal antenna is proposed in [10] for ISM, Wi-Max and IMT frequency bands. In [11] a microstrip patch antenna with slot for RADAR, WLAN, fixed satellite and maritime mobile services is designed that covers frequency range from $2 \mathrm{GHz}$ to $6 \mathrm{GHz}$. Due to the use of thick copper metal plate as ground, the proposed antenna is comparatively heavier. A T-shaped patch antenna is reported in [12] designed on FR4 substrate that operates at $3.5 \mathrm{GHz}, 4.48 \mathrm{GHz}, 6.1 \mathrm{GHz}$ and 8.17 $\mathrm{GHz}$. These operating frequencies are suitable for WiMax, 4G network, WLAN, Satellite \& RADAR communication. In [13] report focuses on UWB antenna design and analysis. Work is done to undertake the area of basics of UWB antenna theory and investigations had been made for the development of UWB antenna from past to present. [14] Reports a multiband antenna using Koch curve in a novel style on the boundary of patch which open a new possible way to use fractal to achieve multiband keeping performance acceptable. In [15] a hexagonal microstrip fractal antenna is reported using step feed structure for ultra wideband application and step feed is used to improve various characteristics. The Hilbert proposed Hilbert Curve in 1891; a year after Peano curve has been proposed by the Peano. The two shapes are sorted as the space filling curve group. The curves utilized permit lessening in the antenna size, along these curves permit reduction of the size while keeping up the performance of antenna [16]. Optimization is the process that can be used to determine the possible optimum dimension of antenna at which antenna will give best output characteristics. In [17] a fractal antenna array is proposed for radio navigation and fixed satellite services, which is optimized using dragonfly optimization. From these techniques DFO [18] with curve fitting is used to optimize proposed antenna. 
In the literature, limited work is reported for the application of RNS and FSS by researchers. A new type of quad band trapezoidal Sierpinski fractal antenna is presented in [19] which works for the frequency range $1.92-2.33 \mathrm{GHz}, \quad 6.53-6.74 \mathrm{GHz}, \quad 9.26-9.47 \mathrm{GHz}$ and $13.18-13.32 \mathrm{GHz}$ having resonating frequency $2.12 \mathrm{GHz}$, $6.6 \mathrm{GHz}, 9.33 \mathrm{GHz}$ and $13.25 \mathrm{GHz}$ respectively. It covers a lot of applications like fixed mobile, satellite, navigation, radiolocation, and space research applications. A newly designed coplanar waveguide fed dual-band antenna is presented in [20] which cover required operating frequency $4.3 \mathrm{GHz}$ with band width of $100 \mathrm{MHz}$ for aircraft radio altimeter. In [21] a microstrip antenna is presented which covers a frequency $4.2 \mathrm{GHz}$ for radio altimeter application, which is used in radio navigational services. In [22] a multilayer antenna is proposed which radiates for two bands: $1.59-1.61 \mathrm{GHz}$ and $2.45-2.52 \mathrm{GHz}$ which covers radio navigation, satellite, radio location, and radio determination applications respectively. Gain is $5.1 \mathrm{~dB}$ and $6.7 \mathrm{~dB}$ at lower and upper resonating frequency respectively. A hybrid fractal antenna with multiband characteristics is proposed in [23] for ARNS and other wireless applications which has a maximum bandwidth of $499 \mathrm{MHz}$. In above-mentioned work, the structure is complicated; bandwidth is narrow and covers the only limited number of bands for RNS and FSS. This paper is focused on the design and development of dedicated high gain multiband antenna with larger bandwidth for RNS and FSS.

The novelty of the proposed antenna lies in its simple and easy to fabricate design which has a multiband performance with wide bandwidth and high gain. The frequency bands of interest for RNS and FSS are 2.7$2.9 \mathrm{GHz}, 4.2-4.4 \mathrm{GHz}, 4.5-4.8 \mathrm{GHz}, 5.725-7.075 \mathrm{GHz}$, 7.25-8.4 GHz, and 8.75-9.5 GHz. Proposed fractal antenna resonates at $2.6 \mathrm{GHz}(2.435-2.6807 \mathrm{GHz}), 4.4$ $\mathrm{GHz}(4.1-4.8 \mathrm{GHz})$ and $8.7 \mathrm{GHz}(5.852-10.05 \mathrm{GHz})$ which covers frequency bands for both RNS and FSS. Use of fractal geometry saved $39.09 \%$ metal area from radiating patch and $20.4 \%$ from ground in comparison of $0^{\text {th }}$ iteration rectangular patch, which make it cost effective also.

\section{Antenna Design and Structure}

The proposed antenna is designed on Rogers RT/duroid $5880(\mathrm{tm})$ substrate of size $55 \mathrm{~mm} \times 60 \mathrm{~mm} \times 3.175 \mathrm{~mm}$, having a dielectric constant 2.2, and loss tangent 0.0009 . The dielectric material Roger $5880(\mathrm{tm})$ is used as substrate material for attaining high gain and high accuracy [2]. The proposed fractal antenna structure consists of third iterative modified Hilbert curve fractal

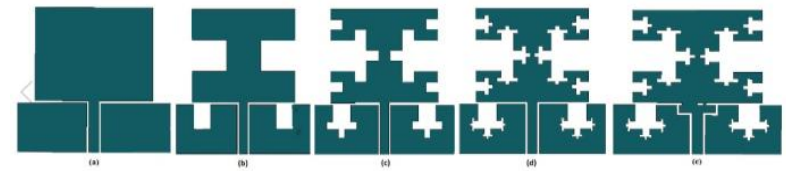

Figure 1: Structure transformation of antenna (a) $0^{\text {th }}$ iteration (b) $1^{\text {st }}$ iteration (c) $2^{\text {nd }}$ iteration (d) $3^{\text {rd }}$ iteration (e) $3^{\text {rd }}$ iteration with modified feed

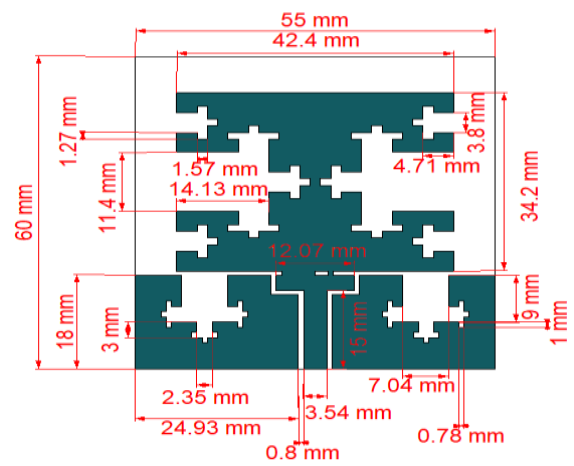

Figure 2: Geometrical description of proposed antenna

loaded rectangular radiator fed by a modified CPW feed. The CPW feed is used in the proposed work for feeding the antenna structure because of its advantages of broadband performance and easy fabrication. The dimension of the feedline are calculated using the standard equations [1][24]. In figure 1 antenna transformation is demonstrated from basic rectangular to final fractal structure.

In the beginning, a standard CPW-fed rectangular antenna has been designed as shown in figure 1(a). In this way, $0^{\text {th }}$ iteration configuration is achieved. Current density at the central part of the radiator is very high in comparison of the current density along the periphery of the radiator that is why radiator and ground are loaded with modified Hilbert curve fractal slots as shown in figure $1(\mathrm{~b})$ to $1(\mathrm{~d})$ which results in $1^{\text {st }}, 2^{\text {nd }}$, and $3^{\text {rd }}$ iteration of the antenna structure. In last step the feed has been modified to step feed as shown in figure 1(e). The microstrip feed dimension is $18.8 \mathrm{~mm} \times 3.54$ $\mathrm{mm}$ and a step feed is created by making width of feed to $12.07 \mathrm{~mm}$ at the end where it feeds the patch. Due to this feed modification bandwidth enhancement has been achieved as such type of techniques also used in UWB antenna to achieve UWB characteristics [13]. The radiating element is connected to step feed using two strips. Width of one strip is kept fixed and by varying the width of second strip, effect on bandwidth of the antenna has been observed and it has been noticed that width of the strip has a significant impact on bandwidth of antenna. Strip width has been varied from a minimum value of $0.4 \mathrm{~mm}$ to a maximum value of 5 $\mathrm{mm}$. Thereafter strip width has been optimized using DFO to obtain optimum bandwidth. In figure 2 all dimensional details of the proposed antenna is shown in $\mathrm{mm}$. 


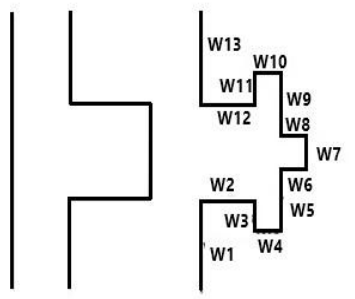

Figure 3: Geometrical details of modified Hilbert curve

\subsection{Iterated function system}

Hilbert curve is modified and used to design the proposed fractal antenna as displayed in Figure 3, whose geometrical details are come by Iterative Function System (IFS) [23]. IFS is a widely used technique for designing of fractal structures.

$$
W(x, y)=\left[\begin{array}{ll}
a & b \\
c & d
\end{array}\right]+\left[\begin{array}{l}
e \\
f
\end{array}\right]
$$

Table 1: IFS Transformation Coefficient

\begin{tabular}{ccccccc}
\hline $\mathrm{W}$ & $\mathrm{a}$ & $\mathrm{B}$ & $\mathrm{c}$ & $\mathrm{d}$ & $\mathrm{e}$ & $\mathrm{f}$ \\
\hline 1 & $1 / 3$ & 0 & 0 & $1 / 3$ & 0 & 0 \\
2 & 0 & $2 / 9$ & $-2 / 9$ & 0 & 0 & $1 / 3$ \\
3 & $-1 / 9$ & 0 & 0 & $-1 / 9$ & $2 / 9$ & $1 / 3$ \\
4 & 0 & $1 / 9$ & $-1 / 9$ & 0 & $2 / 9$ & $2 / 9$ \\
5 & $2 / 9$ & 0 & 0 & $2 / 9$ & $1 / 3$ & $2 / 9$ \\
6 & 0 & $1 / 9$ & $-1 / 9$ & 0 & $1 / 3$ & $4 / 9$ \\
7 & $1 / 9$ & 0 & 0 & $1 / 9$ & $4 / 9$ & $4 / 9$ \\
8 & 0 & $-1 / 9$ & $1 / 9$ & 0 & $4 / 9$ & $5 / 9$ \\
9 & $2 / 9$ & 0 & 0 & $2 / 9$ & $1 / 3$ & $5 / 9$ \\
10 & 0 & $-1 / 9$ & $1 / 9$ & 0 & $1 / 3$ & $7 / 9$ \\
11 & $1 / 9$ & 0 & 0 & $-1 / 9$ & $2 / 9$ & $7 / 9$ \\
12 & 0 & $-2 / 9$ & $2 / 9$ & 0 & $2 / 9$ & $6 / 9$ \\
13 & $1 / 3$ & 0 & 0 & $1 / 3$ & 0 & $6 / 9$ \\
\hline
\end{tabular}

For self-relative fractal structure, the portions are created at every iteration of same measurements are determined using equation (2). Coefficients of the IFS transformation for the proposed fractal antenna are given in Table I.

\subsection{Curve Fitting}

In literature step feed is used as a technique to enhance the bandwidth of patch antennas. In this work, the step feed has been used in a novel way to enhance the bandwidth of the proposed antenna. After changing conventional feed to step feed, it is connected to the radiator using two strips, each having a width of $5 \mathrm{~mm}$. Thereafter, by keeping the width of one strip fixed and changing the width of second strip, effect on bandwidth of the antenna has been observed and it has been noticed that width of the strip has a significant impact on bandwidth of antenna. Strip width has been varied from a minimum value of $0.4 \mathrm{~mm}$ to a maximum value of $5 \mathrm{~mm}$. There is no direct relation between the strip width and bandwidth of antenna. To establish a relation between the above said parameters, the mathematical modeling of the antenna is done using Curve Fitting Method in MATLAB. First of all a data set of bandwidth and strip width is generated by simulating the antenna in HFSS environment. Strip width has been varied from a minimum value of $0.4 \mathrm{~mm}$ to a maximum value of $5 \mathrm{~mm}$ and at each step change in bandwidth has been observed then Curve fitting has been used to investigate the best fit mathematical function to the acquired data set and modeled as given in equation (3). Bandwidth can be estimated through Reflection Coefficient $\left(\mathrm{S}_{11}\right)$ parameter of antenna. Frequency range for which the value of $S_{11}$ curve fall below the $-10 \mathrm{~dB}$ is called the bandwidth of antenna. To assess the antenna bandwidth $\mathrm{N}$ frequency samples have been chosen in the required frequency range. By counting the samples whose value is less than or equals to - $10 \mathrm{~dB}$, the bandwidth of proposed antenna has been assessed. The mathematical representation of the conditions is given below:

$$
\begin{gathered}
\mathrm{S} 11=\left\{\begin{array}{ll}
0 & \mathrm{~s} 11>-10 \\
1 & \mathrm{~s} 11 \leq-10
\end{array}\right\} \\
\mathrm{BW}=\mathrm{S} 11\left(\mathrm{f}_{1}\right)+\mathrm{S} 11\left(\mathrm{f}_{2}\right) \ldots \ldots \ldots \ldots \mathrm{S} 11\left(\mathrm{f}_{\mathrm{N}}\right) .
\end{gathered}
$$

It reveals from the function that if the $\mathrm{S}_{11}$ is less than or equals to $-10 \mathrm{~dB}$ than it will be counted as 1 else $S_{11}$ will be counted as 0 .

$\mathrm{BW}=0.27 \mathrm{x}^{5}-4 \mathrm{x}^{4}+22 \mathrm{x}^{3}-55 \mathrm{x}^{2}+57 \mathrm{x}+23$

Where, $\mathrm{x}$ is width of the strip and $\mathrm{BW}$ is the bandwidth of antenna. In the next section, the proposed antenna modeled by equation (3) is optimized using Dragonfly optimization method, introduced recently in the year 2015[18].

\subsection{DFO}

Dragonfly optimization method proposed in is swarm intelligence (SI) based method which is capable to outperform the present well known SI based methods [18]. Therefore DFO is used to optimize antenna problem in this work to open a new window to use in the field of antenna engineering. Dragonfly Optimization Method [18] mimics the static and dynamic swarming behavior of dragonflies. In static swarm, dragonflies fly over a small region to hunt. Local migration and abrupt changes in path are main characteristics of a static swarm. In dynamic swarm, dragonflies form the swarm to migrate over a long distance in one direction. These two acts are similar to exploration and exploitation phase of optimization techniques. In this two vectors are considered for 
updating the position of search agents which are called as step vector $(\Delta X)$ and position vector $(X)$. Step vector $(\Delta X)$ shows the direction of the shift of the dragonflies and is defined in as follows:

$\Delta \mathrm{X}_{\mathrm{k}+1}=\left(\mathrm{sS}_{\mathrm{j}}+\mathrm{aA}_{\mathrm{j}}+\mathrm{cC}_{\mathrm{j}}+\mathrm{fF}_{\mathrm{j}}+\mathrm{eE}_{\mathrm{j}}\right)+\mathrm{w} \Delta \mathrm{X}_{\mathrm{k}}$

where $\mathrm{w}$ is the inertia weight of search agent, $\mathrm{S}_{\mathrm{i}}, \mathrm{A}_{\mathrm{i}}, \mathrm{C}_{\mathrm{i}}$, $\mathrm{F}_{\mathrm{i}}$, and $\mathrm{E}_{\mathrm{i}}$ indicates the separation, cohesion, alignment, food source and enemy of the i-th individual respectively and $\mathrm{s}, \mathrm{a}, \mathrm{c}, \mathrm{f}$, and $\mathrm{e}$ are separation, alignment, cohesion, food factor and enemy factor weights respectively. Position vector are computed using step vector by the following equation:

$$
\mathrm{X}_{\mathrm{k}+1}=\mathrm{X}_{\mathrm{k}}+\Delta \mathrm{X}_{\mathrm{k}+1}
$$

Where, $\mathrm{k}$ is the current iteration

To improve the randomness, stochastic behavior and exploration of the artificial dragonflies, the concept of random walk called levy flight. If search agent (Dragonfly) is alone than it will change its location by using Levy flight, with the following equation:

$$
\mathrm{X}_{\mathrm{k}+1}=\mathrm{X}_{\mathrm{k}}+\operatorname{Levy}(\mathrm{d}) \times \mathrm{X}_{\mathrm{k}}
$$

Here $\mathrm{d}$ is the dimension of position vectors.

Based on above considerations, the Dragonfly Optimization Algorithm is executed in MATLAB using following fitness function obtained from equation (3) for the optimization of simulated antenna

Fitness function $=(52-\mathrm{BW})^{2}$

Table 2: Parameters value taken for Dragonfly optimization

\begin{tabular}{lc}
\hline \multicolumn{1}{c}{ Parameter } & Value \\
\hline No. of Search Agents & 100 \\
Lower Bound & 0.4 \\
Upper Bound & 5 \\
Dimensions & 1 \\
Maximum Iterations & 500 \\
Optimized Value & 0.9 \\
\hline
\end{tabular}

The parameters value is shown in table II which are taken for DFO when it is used to optimize the dimension of the proposed antenna.

\section{Results and Discussions}

Performance evaluation and design of the proposed antenna is done using HFSS. The performance of the antenna is evaluated at each and every stage of design. The designed fractal antenna is simulated up to third iteration of proposed modified Hilbert curve fractal to achieve the desired results and to study the effect of number of iteration on performance parameter. For the proposed fractal antenna the Reflection Coefficient values for all iterations are shown in figure 4 . For $0^{\text {th }}$ iteration the designed antenna resonates at $2.6 \mathrm{GHz}$ (2.4314-2.7134 GHz), and at 7.6 GHz (7.2876-8.0586 $\mathrm{GHz}$ ), for first iteration resonance occurs at $5 \mathrm{GHz}$ (4.8078- $5.9 \mathrm{GHz})$, and $9.4 \mathrm{GHz}(8.9855-10 \mathrm{GHz})$, for $2^{\text {nd }}$ iteration the simulated result shows resonance at 2.6 $\mathrm{GHz}(2.5121-2.7499 \mathrm{GHz}), 4.6 \mathrm{GHz}, 5.1 \mathrm{GHz}$ (4.5034$5.4929 \mathrm{GHz}), 6.2 \mathrm{GHz}(6.0778-6.4299 \mathrm{GHz}), 8.1 \mathrm{GHz}$ (7.8949-8.2367 GHz) and $9.2 \mathrm{GHz}$ (9.0579$9.3893 \mathrm{GHz})$, simulation result for the $3^{\text {rd }}$ iteration of modified fractal antenna shows resonance at $2.5 \mathrm{GHz}$ (2.4-2.69 GHz), $4.3 \mathrm{GHz}(4.27-4.43 \mathrm{GHz}), 4.7 \mathrm{GHz}$ $(4.63-4.83 \mathrm{GHz}), 6.1 \mathrm{GHz}(5.88-7.05 \mathrm{GHz})$ and at 8.9 $\mathrm{GHz}(8.83-9.03 \mathrm{GHz})$. It is noticed that there is a little improvement in the $3^{\text {rd }}$ iteration than in the $2^{\text {nd }}$ iteration, and owing to fabrication limits, therefore next iterations are not analyzed. To achieve further better results in terms of bandwidth, the feed of the antenna is modified and optimized. The optimized results show expected improvement in results and optimized antenna resonates at $2.6 \mathrm{GHz}(2.435-2.6807 \mathrm{GHz}), 4.4 \mathrm{GHz}(4.1-4.8 \mathrm{GHz})$ and $8.7 \mathrm{GHz}(5.852-10.05 \mathrm{GHz})$ as shown in figure 4 .

Proposed antenna is fabricated for the validation of simulated results. The proposed antenna resonates at $2.6 \mathrm{GHz}, 4.4 \mathrm{GHz}$, and $8.7 \mathrm{GHz}$ having Reflection Coefficient of $-11.96 \mathrm{~dB},-13.08 \mathrm{~dB}$ and $-27.18 \mathrm{~dB}$ respectively in simulation while as the measured results of fabricated antenna resonates at $2.6 \mathrm{GHz}, 4 \mathrm{GHz}$, and at $8.3 \mathrm{GHz}$ having Reflection Coefficient of $-24.4 \mathrm{~dB}$, $17.6 \mathrm{~dB}$, and $-24.9 \mathrm{~dB}$ respectively. The bandwidth of all three bands is of $245.7 \mathrm{MHz}, 700 \mathrm{MHz}$, and $4198 \mathrm{MHz}$ respectively in simulation while as in measured results the bandwidth of all three bands are $310 \mathrm{MHz}, 590$ $\mathrm{MHz}$, and $4010 \mathrm{MHz}$ respectively.

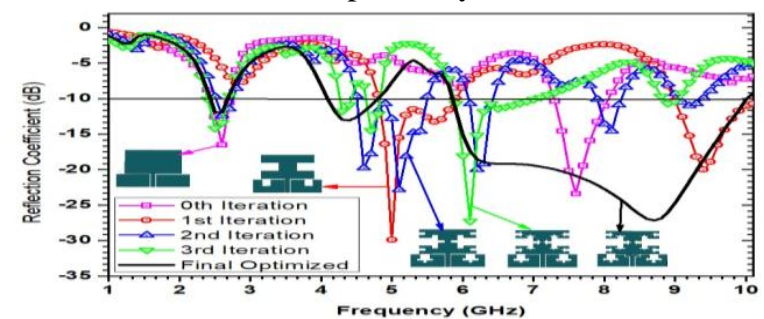

Figure 4: Reflection Coefficient for all iterations of the proposed antenna

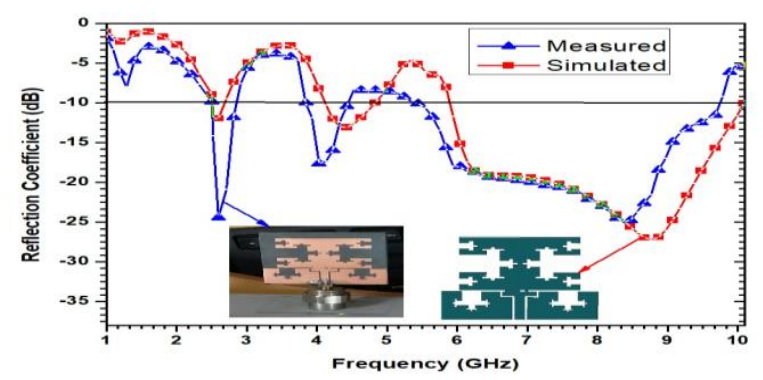

Figure 5: Measured and Simulated Reflection Coefficient of the proposed antenna 
Measurement of $\mathrm{S}_{11}$ is done using Vector Network Analyzer made of Anritsu (Model No. MS46322A). Figure 5 shows the simulated and measured Reflection Coefficient plot of proposed antenna which are in good agreement. Current distribution is shown in figure 6 at all resonating frequencies. Figure 6(a) represent the current distribution at $2.6 \mathrm{GHz}$, figure $6(\mathrm{~b})$ represent the current distribution at $4.4 \mathrm{GHz}$, and figure 6(c) represent the current distribution at $8.7 \mathrm{GHz}$. It has been observed that the current is distributed uniformly over the surface of radiating patch, ground and feed.
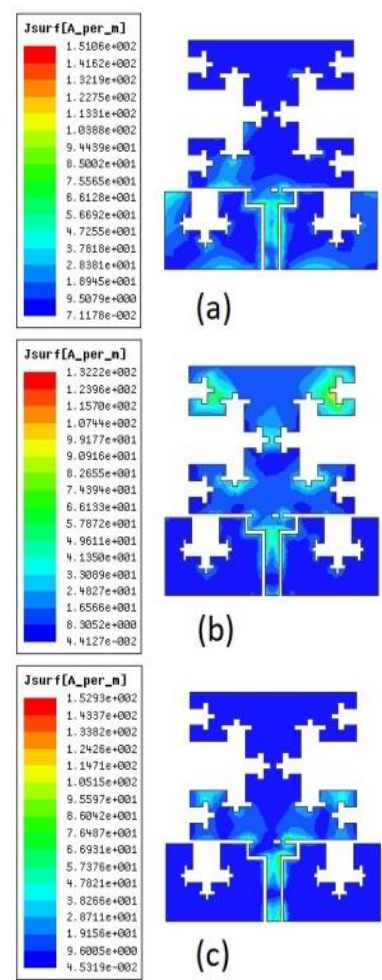

(a)

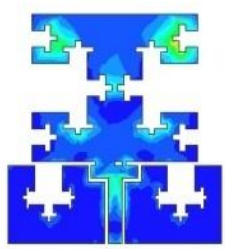

(b)

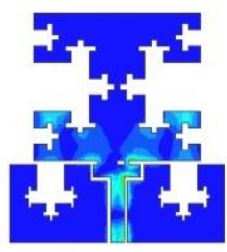

(c)

Figure 6: Current distribution of proposed antenna (a) at $2.6 \mathrm{GHz}$ (b) at $4.4 \mathrm{GHz}$ (c) at $8.7 \mathrm{GHz}$
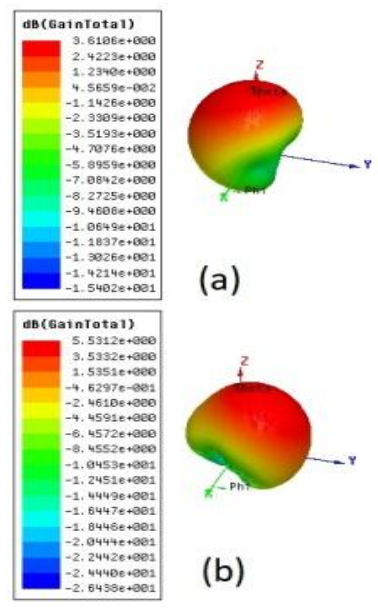

(a)

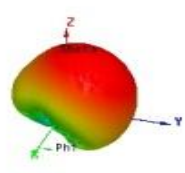

(b)

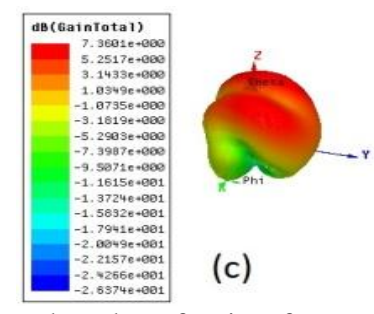

Figure 7: 3-D Polar plot of gain of proposed antenna (a) at $2.6 \mathrm{GHz}$ (b) at $4.4 \mathrm{GHz}$ (c) at $8.7 \mathrm{GHz}$

Table 3. Comparison of the proposed antenna with existing antennas

\begin{tabular}{|c|c|c|c|c|c|}
\hline $\begin{array}{c}\text { Reference } \\
\text { No. }\end{array}$ & $\begin{array}{c}\mathrm{f}_{\mathrm{r}} \\
(\mathrm{GHz})\end{array}$ & $\begin{array}{c}\text { BW } \\
(\mathrm{GHz})\end{array}$ & $\begin{array}{l}\text { Gain } \\
(\mathrm{dB})\end{array}$ & $\begin{array}{l}\text { Dime } \\
\text { nsion }\end{array}$ & $\begin{array}{l}\text { Substrate } \\
\text { Materia }\end{array}$ \\
\hline [19] & $\begin{array}{c}2.12 \\
6.6 \\
9.33 \\
13.25\end{array}$ & $\begin{array}{l}0.420 \\
0.210 \\
0.210 \\
0.140\end{array}$ & $\begin{array}{c}5.56 \\
4.41 \\
4.56 \\
6\end{array}$ & $\begin{array}{l}37.65 \\
\times 27.0 \\
7 \times 0.8\end{array}$ & FR4 \\
\hline [20] & $\begin{array}{l}1.8 \\
4.3 \\
\end{array}$ & $\begin{array}{l}0.317 \\
0.143\end{array}$ & $\begin{array}{l}- \\
-\end{array}$ & $\begin{array}{l}50 \times 5 \\
2 \times 1.6\end{array}$ & FR4 \\
\hline [21] & $\begin{array}{l}4.36 \\
9.09\end{array}$ & $\begin{array}{l}0.100 \\
0.730\end{array}$ & $\begin{array}{l}7.44 \\
6.57\end{array}$ & $\begin{array}{c}\text { Radiu } \\
\text { s of } \\
\text { patch } \\
= \\
13.77\end{array}$ & $\begin{array}{c}\text { RT- } \\
\text { Duroid }\end{array}$ \\
\hline [22] & $\begin{array}{c}1.6 \\
2.485\end{array}$ & $\begin{array}{l}0.20 \\
0.70\end{array}$ & $\begin{array}{l}5.1 \\
6.7\end{array}$ & $\begin{array}{l}107.5 \\
\times 78 \times \\
7.874\end{array}$ & $\begin{array}{c}\text { Five } \\
\text { layered } \\
\text { substrate }\end{array}$ \\
\hline [23] & $\begin{array}{c}1.236 \\
2.46 \\
4.1818 \\
5.409 \\
6.7591 \\
8.1091 \\
9.3363\end{array}$ & $\begin{array}{l}0.283 \\
0.475 \\
0.499 \\
0.480 \\
0.385 \\
0.376 \\
0.456\end{array}$ & $\begin{array}{l}\text { Max } \\
\text { gain } \\
=4\end{array}$ & $\begin{array}{c}28 \times 1 \\
5 \times 1.5 \\
8\end{array}$ & FR4 \\
\hline $\begin{array}{l}\text { Proposed } \\
\text { antenna }\end{array}$ & $\begin{array}{l}2.6 \\
4.4 \\
8.7\end{array}$ & $\begin{array}{l}0.245 \\
0.700 \\
4.198\end{array}$ & $\begin{array}{l}3.6 \\
5.5 \\
7.3\end{array}$ & $\begin{array}{c}55 \times \\
60 \times \\
3.175\end{array}$ & $\begin{array}{l}\text { RT/duroi } \\
\text { d } 5880\end{array}$ \\
\hline
\end{tabular}

The maximum current density is observed in the feed, at the edges of the ground plane, which are electromagnetically coupled to the feed and around the edges of the fractal slots in radiating patch and ground. Figure 7 shows the 3-D polar plot of gain of the proposed antenna. Figure 7(a) shows the gain at 2.6 $\mathrm{GHz}$, figure $7(\mathrm{~b})$ shows the gain at $4.4 \mathrm{GHz}$ and figure 7 (c) shows the gain at $8.7 \mathrm{GHz}$. The simulated gain of the antenna at $2.6 \mathrm{GHz}, 4.4 \mathrm{GHz}$ and $8.7 \mathrm{GHz}$ is $3.6 \mathrm{~dB}$, $5.5 \mathrm{~dB}$, and $7.3 \mathrm{~dB}$ respectively. 


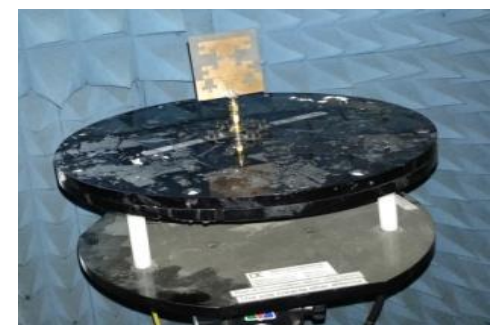

Figure 8: Fabricated antenna in anechoic chamber

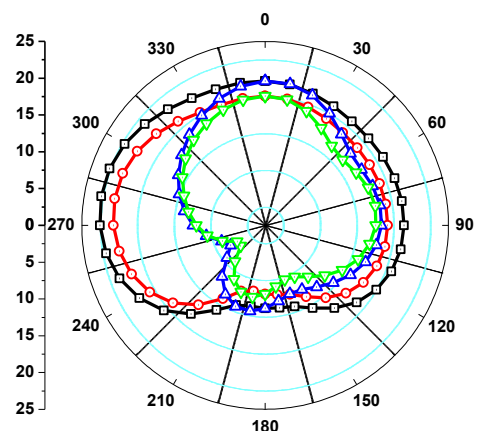

$$
\begin{aligned}
& -\square-\text { Simulated E-Plane at } 2.6 \mathrm{GHz} \\
& -- \text { - Measured E-Plane at } 2.6 \mathrm{GHz} \\
& -\triangle-\text { Simulated H-Plane at } 2.6 \mathrm{GHz} \\
& -\nabla \text { - Measured H-Plane at } 2.6 \mathrm{GHz}
\end{aligned}
$$

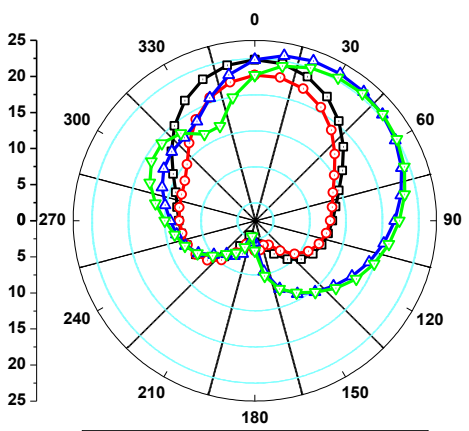

- - Simulated E-Plane at $4.4 \mathrm{GHz}$ $-\odot-$ Measured E-Plane at $4.4 \mathrm{GHz}$ $\triangle$ - Simulated H-Plane at $4.4 \mathrm{GHz}$ $\checkmark$ - Measured $\mathrm{H}$-Plane at $4.4 \mathrm{GHz}$

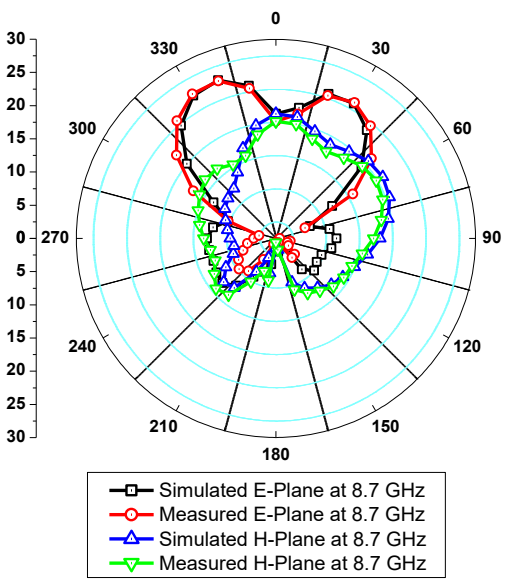

Figure 9: Simulated and Measured Radiation Pattern of the proposed antenna
Since the current distribution change with change in frequency as it is more condensed in the lower left portion of radiator at $2.6 \mathrm{GHz}$ and at 4.4 it is nearly equally distributed on the radiator while as at $8.7 \mathrm{GHz}$ the current is more condensed in lower portion of radiator as shown in figure 6, the radiation patterns slightly change with change in frequency. Measurement of radiation pattern has been done in anechoic chamber in receiving mode. Fabricated antenna in anechoic chamber is shown in figure 8. Measured E-plane and $\mathrm{H}$ plane radiation pattern are shown in figure 9 with simulated E-plane and H-plane radiation pattern. Simulated and measured radiation patterns of the proposed antenna are shown together for verification at all three resonating frequencies: $2.6 \mathrm{GHz}, 4.4 \mathrm{GHz}$ and $8.7 \mathrm{GHz}$. It has been observed that the simulated and measured radiation patterns are very close to each other. In addition to the above-discussed characteristics, the proposed antenna is compared with the existing antennas for RNS and FSS in table 3. The proposed fractal antenna has a compact size, multiband performance with wide bandwidth and high gain as compared to antenna proposed in [19][20][21][22] and [23].

\section{Conclusions}

A triple band modified Hilbert curve fractal antenna is proposed in this report for Radio Navigation and Fixed Satellite Services. The application of modified Hilbert curve to the antenna design translates it into multiband antenna and in addition to this the optimized modified CPW feed improves the bandwidth significantly. The main advantages of the proposed work is multiband performance with wide bandwidth, high gain and easy to design technique.

\section{Acknowledgment}

The authors would like to thank to the Electronics and Communication Engineering department of Sant Longowal Institute of Engineering \& Technology, Punjab, India for providing kindly support and excellent lab facilities.

\section{REFERENCE}

[1] C. Balanis, Antenna Theory - Analysis and Design. 1997.

[2] R. Garg, P. Bhartia, I. Bahl, and A. Ittipiboon, Microstrip antenna design handbook. 2001.

[3] B. B. Mandelbrot, "The fractal geometry of nature /Revised and enlarged edition/," New York, 1983.

[4] D. H. Werner and S. Ganguly, "An overview of fractal antenna engineering research," IEEE Antennas Propag. Mag., vol. 45, no. 1, pp. 38-57, 2003.

[5] M. Tarbouch, A. E. L. Amri, H. Terchoune, and O. Barrou, "Trial of H-Tree Fractal Slots in The 
Ground Plane of A Micropstrip Patch Antenna," Int. J. Microw. Opt. Technol., vol. 13, no. 1, pp. 51-60, 2018.

[6] S. Rani and A. P. Singh, "Modified Koch fractal antenna with asymmetrical ground plane for multi and UWB applications," Int. J. Appl. Electromagn. Mech., vol. 42, no. 2, pp. 259-267, 2013.

[7] V. V Reddy, "Broadband Koch Fractal Boundary Printed Slot Antenna for ISM Band Applications," Adv. Electromagn., vol. 7, no. 5, 2018.

[8] R. A. S. Hassan M. Elkamchouchi, "Triple Band Microstrip Patch Antenna with I Slot For Radar Altimeter Applications," IOSR J. Electron. Commun. Eng., vol. 11, no. 3, pp. 53-57, 2016.

[9] Sachin Chauhan, J. K. Deegwal, and R. Gera, “A Design of Triangular Sierpinski Gasket Fractal Antenna," Int. J. Electron. Commun. Technol., vol. 4, pp. 62-64, 2013.

[10]D. E. L. Nabaoui, A. Tajmouati, J. Zbitou, A. Errkik, and A. Mediavilla, "A New Design of a Low Cost Multiband Fractal CPW-Fed Antenna," Int. J. Microw. Opt. Technol., vol. 1, no. 1, pp. 1-7, 2018.

[11] P. A. Ambresh, P. M. Hadalgi, and P. V. Hunagund, "Planar microstrip slot antenna for S \& C band wireless applications," in Journal of Physics: Conference Series, 2013, vol. 435, no. 1.

[12] M. Kaur, A. P. D. Singh, and G. S. Gill, "Design of T-Shaped Fractal Patch Antenna for Wireless Applications," Int. J. Res. Eng. Technol., vol. 4, no. 9, pp. 401-405, 2015.

[13] E. G. Lim, Z. Wang, C. U. Lei, Y. Wang, and K. L. Man, "Ultra wideband antennas - past and present," IAENG Int. J. Comput. Sci., vol. 37, no. 3, 2010.

[14] M. Gupta and V. Mathur, "Koch boundary on the square patch microstrip antenna for ultra wideband applications," Alexandria Engineering Journal, 2017.

[15] K. K. Sawant and C. R. S. Kumar, "CPW fed hexagonal micro strip fractal antenna for UWB wireless communications," AEU - Int. J. Electron. Commun., vol. 69, no. 1, pp. 31-38, 2014.

[16] K. J. Vinoy, K. A. Jose, V. K. Varadan, and V. V. Varadan, "Hilbert curve fractal antenna: A small resonant antenna for $\mathrm{VHF} / \mathrm{UHF}$ applications," Microw. Opt. Technol. Lett., vol. 29, no. 4, pp. 215-219, 2001.

[17] A. Kumar and A. Partap, "On the Design of $2 \times 2$ Element Fractal Antenna Array using Dragonfly Optimization," Int. J. Comput. Appl., vol. 179, no. 33, pp. 27-34, Apr. 2018.

[18] S. Mirjalili, "Dragonfly algorithm: a new metaheuristic optimization technique for solving singleobjective, discrete, and multi-objective problems," Neural Comput. Appl., vol. 27, no. 4, pp. 10531073, 2016.

[19] M. Ram, S. Das, and R. L. Yadava, "A Quad Band Sierpinski Trapezoidal Fractal Patch Antenna for Wireless Applications," J. Microwaves, Optoelectron. Electromagn. Appl., vol. 16, pp. 2537, 2017.

[20] T. Phasithjirakul, T. Wannasirimongkol, A. Namsang, R. Lerdwanittip, and P. Chomthong, "Design of a dual-band Verre de Champagne Fractal CPW antenna for LTE and aircraft altimeter application," in ISAP 2016 - International Symposium on Antennas and Propagation, 2017.

[21] K. RamaDevi, A. M. Prasad, and A. Jhansi Rani, "Design of A Pentagon Microstrip Antenna for Radar Altimeter Application," Int. J. Web Semant. Technol., vol. 3, pp. 31-42, 2012.

[22] P. R. Prajapati, A. Patnaik, and M. V. Kartikeyan, "Design of single feed dual band dual polarized microstrip antenna with defected ground structure for aeronautical and radio navigation applications," in 2014 31th URSI General Assembly and Scientific Symposium, URSI GASS 2014, 2014.

[23] Y. Kumar and S. Singh, "A Compact Multiband Hybrid Fractal Antenna for Multistandard Mobile Wireless Applications," Wirel. Pers. Commun., vol. 84, no. 1, pp. 57-67, 2015.

[24] S. Singhal and A. K. Singh, "CPW-fed octagonal super-wideband fractal antenna with defected ground structure," IET Microwaves, Antennas Propag., 2017. 